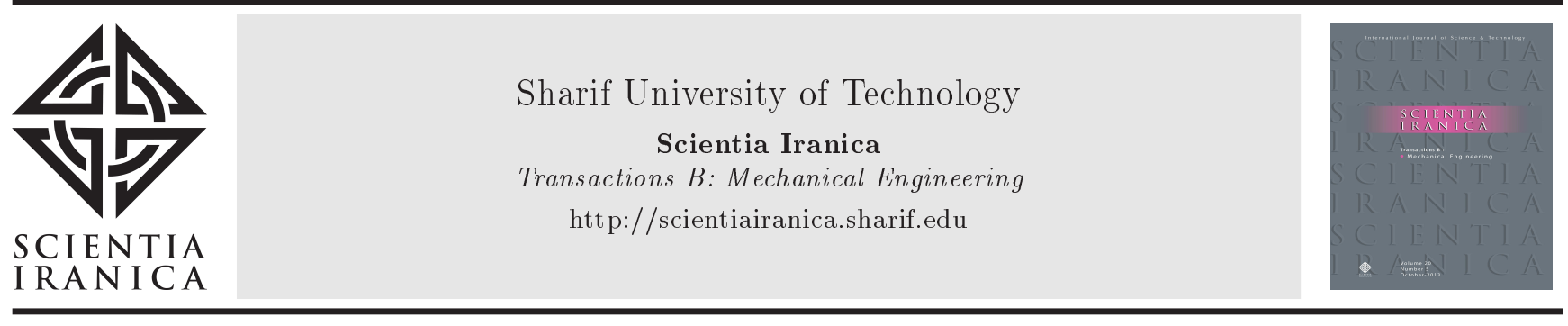

\title{
Experimental determination of fracture toughness of woven/chopped glass fiber hybrid reinforced thermoplastic composite laminates
}

\author{
A.O. Ozdemir* and C. Karataş \\ Faculty of Technology, Gazi University, 06500, Ankara, Turkey. \\ Received 11 July 2020; received in revised form 28 September 2020; accepted 7 December 2020
}

\section{KEYWORDS \\ Compact tension; \\ Damage evolution; \\ Fracture toughness; \\ Hybrid reinforced; \\ Thermoplastic \\ composite laminates.}

\begin{abstract}
Today the polymer composites have a special standing and widespread application in engineering practices. The industrial application of different materials requires the identification of their properties. Also, the safe formation of laminated composites requires detrimental factors to the identified. This requirement comes to be a source of motivation for researchers to investigate the propagation characteristic of cracks to explore the detrimental factors. Thus in the present study, the fracture toughness of the composite structure was investigated by performing compact tensile and compact compression tests for hybrid fiber reinforced polypropylene composite laminates which have three types of composition with various thicknesses, fiber contents, and woven and/or chopped glass fiber reinforcement. The critical energy release rates of fiber and matrix in both tensile and compressive fracture cases were determined in pre-cracked specimens under plane-strain loading conditions. In the present study, the longitudinal fiber breakage/buckling and the transverse matrix crack/crushing are defined as the damage mechanisms of the composite materials. As a result of the longitudinal tension, the damage progressed gradually in the form of translaminar fiber breaking in materials containing continuous fibers. In the transverse tension process, fiber-matrix separation caused intralaminar deformation in the materials. The highest fracture critical energy release rate was found in the material with the maximal fiber layer.
\end{abstract}

(C) 2021 Sharif University of Technology. All rights reserved.

\section{Introduction}

Polymer composites as lightweight materials have been emerged as preferred choices for automotive, aerospace, and energy engineering applications, because of their high specific strength and corrosion resistance $[1,2]$. The weight reduction studies to reduce fuel consumption are gaining interest in the automotive industry, and the use of polymer fiber-reinforced composites in-

*. Corresponding author. Tel.: +905322361266

E-mail address: onurozdemir@gazi.edu.tr (A.O. Ozdemir)

doi: $10.24200 /$ sci.2020.56380.4701 stead of metal materials received a great deal of attention due to their high specific strength [3]. Polymers are classified as plastics and elastomers, and the plastics are divided into two groups based on their behavior toward heat, including thermoplastic and thermosetting materials [4]. Today, thermoset-based polymer composite materials are used in vehicles, but they have some disadvantages such as being non-recyclable and being brittle. Moreover, the mass production of these materials is a time-consuming task. The predominant use of thermoplastic polymers is common practice in daily life and its use is becoming more prevalent in commercial products [5]. The thermoplastic composites do offer potential advantages over thermosets composites 
(d) Transverse intralaminar (e) Translaminar matrix crack crack progression

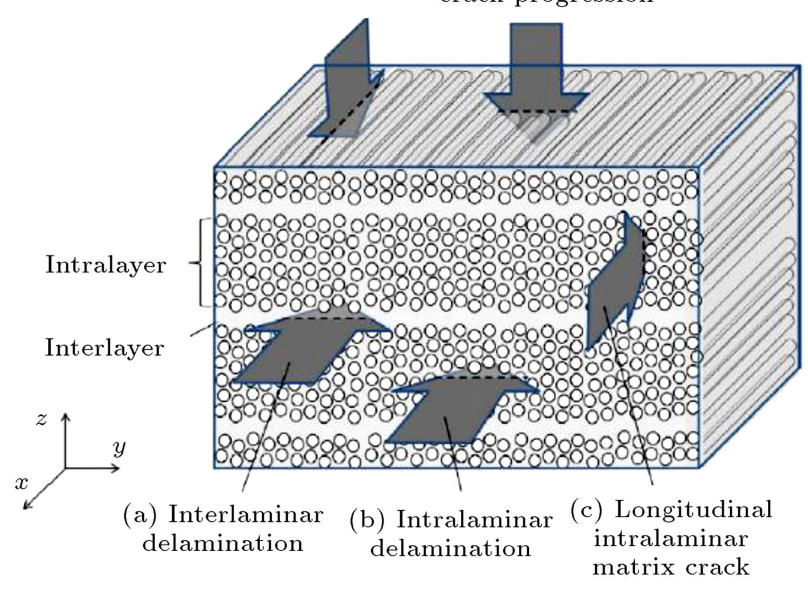

Figure 1. Schematic drawing of failure modes.

some of which include higher toughness, reformability, short process cycle times, and recyclability. These advantages caused them to be preferred over thermosets composites. The anisotropic mechanical behaviour of the composite materials follows from their nonhomogeneous composition [6]. The fracture toughness associated with the tensile/compressive failures matters in terms of the composite material characterization and finite element analyses [7]. Test standards are developed to determine these specific properties. Thus, the researchers focused on defect resistance [8]. As illustrated in Figure 1, the failure forms are various some of which include the interlaminar or intralaminar delaminations, longitudinal or transverse intralaminar matrix cracks, and translaminar fiber breaking [9]. The interlaminar delamination is not considered in this investigation. This delamination is associated with the fracture toughness of debonding, which is determined by the tests called mode-I and mode-II tests [10].

The fracture toughness value is mostly dependent on the fiber configuration. To determine the effect of the fracture energy change following from the crack growth, various tests are used some of which include: compact tension/compression test, four/three-point bending test, double/single-edge notched tension test, extended compact tension test, and center notched tension experiments. The field literature contains some illustrations to these tests [11-13]. The compact tension test was normally standardized by the ASTME399 for fracture toughness of the metallic materials, and it was followed by a similar test process developed by ISO-13586. This test method was used by Ma et al. to investigate the effects of inorganic nanoparticles on the fracture toughness and the toughening mechanism of epoxy systems, as well as it is applied by Trappe et al. to analyse the relationship between epoxy resin process and crack resistance $[14,15]$. Pinho et al. evaluated the fracture toughness of the multilayered composite sheets using the compact tension method; also, this method was adapted to the compression situation. They measured the tensile and compressive critical energy release rates of the aligned fiber, the value of which was determined to be equal to $0 / 90$. They determined the start and growth of fiber failure [16]. Katafiasz et al. made effort to show that the energybased modelling techniques require fracture toughness properties, in cases where the stress-based models are assumed to be insufficient in modelling the extent of the damage. In agreement with this approach, in the recent researches conducted on the fracture toughness properties, the employment of the compact tension technique is considered [17]. Although the damage criteria of short fiber-reinforced composites are mostly estimated using a physical-based approach (the relationship between delamination length and damage and strength), the translaminar fracture toughness is specifically investigated for the failure model of unidirectional multi-layer composite laminates [18]. The energy release of debonding and friction is thought to be associated with the hierarchical structure between the layer surfaces. Modifications have been made in the structure of composite laminates to increase fracture resistance and tolerance, and the effects of materials on the fracture toughness have been estimated using analytical models and validated by experimental studies [19]. It was determined that the fracture resistance changes linearly as a function of the layer thickness, and its increasing thickness provides the distribution of the stress concentration around the notch; moreover, thin-plies composites were found to exhibit semi-isotropic behavior and micro-crack models affect damage tolerance [20]. Duigou et al. manufactured biopolymer composite laminates from prepregs with a $0 / 90^{\circ}$ configuration using unidirectional glass fiber. To compare the different fracture toughness values of composites, the different cooling rates for the film stacking manufacturing are taken as criteria. The ISO-13586 test was used to determine the fracture toughness. The fracture toughness of slow-cooled materials was reduced due to the improvement of the crystallinity of the thermoplastic matrix [21]. Kinloch et al. carried out fracture tests according to ISO-13586 to determine the effect of the addition of nano and microparticles to epoxy resin on the toughness mechanisms of natural continuous fiber and woven fabric reinforced composites [22]. Specimens are monitored with Cscan, X-ray, and Digital Image Correlation systems to verify the spread of the crack and the stress/strain distribution of the damage zone [23]. Also, in fiber reinforced polymer composites, the intralaminar fracture toughness was characterized for woven laminates, and fracture mechanism was studied for cross-linked epoxy resins $[24,25]$. Some recent investigations proceeded to the issues such as the complex kinematic relationships, 
damage models related to failure criteria, and adhesion behaviors associated with delamination. These studies resulted in the improvement of the above-mentioned failures to some extent, however, further research is needed to estimate and overcome these intralaminar and translaminar fractures [26].

In the studies on fracture characterization, there are composites reinforced with nanofibers, unidirectional, multidirectional or two-dimensional woven fabrics. In addition, research on thermoset matrix impregnated composites is in the majority. This is true of the thermoset composites because in spite of the fact that they were considered in some researches, the scarcity of the studies conducted on the fracture toughness of thermoplastic composites is very evident. The composite laminates investigated in the present study contain both chopped and woven fibers and the arrangement of their different weaving density is proportional to the related directions. The originality of the present study lies in these properties which distinguish the composite laminates under discussion from conventional composites. Although woven reinforced composites provide high strength, they have a low degree of flexibility. On the other hand, chopped fiber reinforcements are flexible at a level close to that of plastics, but their strength is relatively low. The chopped fiber is cheaper and can easily be used in high volume production. The chopped fiber also gives formability, when it is used with woven reinforcement providing strength. Hybrid composites have been the focus of many studies in recent years [27]. In the present study, the fracture toughness of hybrid thermoplastic composite laminates was determined using the compact tension/compression method. The compact tension test is used to characterize the fracture behavior and failure crack growth data. The composite materials have three different compositions having various thicknesses and fiber contents, the matrix element being polypropylene and woven and/or chopped glass fiber reinforcement. The tensile and compressive loadings were applied to composite laminates along with the 0 and $90^{\circ}$ directions. The force-displacement changes of the materials were measured and then damage evolutions and elastic moduli were calculated. The effects of composite laminate thickness, fiber type, ratio, and direction on the fracture behaviour were examined comparatively.

\section{Experimental procedure}

\subsection{Material}

In this study, three types of thermoplastic composite laminates with different constructions were examined. The materials became available by the manufacturers in the form of semi-finished products in flat plate shape. In this regard, a two-step manufacturing process is required where the first step involves impregnating the fibers with polypropylene resin and then compression molding during a second step. The properties of the specimens that differ according to fiber ratio and architecture are given in Table 1. The GMT and GMTex products manufactured by Quadrant Plastic Composites AG were used. The S1 contained only a glass fiber mat. The S2 and S3 contained continuous fiber in addition to the glass mat. The structural properties of the materials are determined by the manufacturer and also the fiber ratios are verified by thermogravimetric-analysis.

The fiber ratios and thicknesses of S1, S2, and S3 specimens were $30 \%-4.8 \mathrm{~mm}, 39 \%-4.8 \mathrm{~mm}$, and $57 \%-4.3 \mathrm{~mm}$, respectively. The fiber distribution and weaving style of fibers in the composite ply for S2 and

Table 1. Materials structural properties.

\begin{tabular}{|c|c|c|c|}
\hline & Material-I (S1) & Material-II (S2) & Material-III (S3) \\
\hline \multicolumn{4}{|l|}{ Material types } \\
\hline Resin matrix & \multicolumn{3}{|c|}{ Polypropylene (PP) } \\
\hline Reinforcement & \multicolumn{3}{|c|}{ E-Glass fabric } \\
\hline Weaving style & Mat (non-woven) & \multicolumn{2}{|c|}{ Plain } \\
\hline Fiber distribution & $\begin{array}{c}\text { Chopped long fiber } \\
50-100 \mathrm{~mm}\end{array}$ & $\begin{array}{c}\text { Two layers woven } \\
\text { and chopped }\end{array}$ & $\begin{array}{c}\text { Four layers woven } \\
\text { and chopped }\end{array}$ \\
\hline Yarn density & Random & \multicolumn{2}{|c|}{$x \uparrow 80 \% \& y \rightarrow 20 \%$} \\
\hline Fiber ratio $\%$ weight & 30 & 39 & 57 \\
\hline Thickness (mm) & 4.8 & 4.8 & 4.3 \\
\hline
\end{tabular}



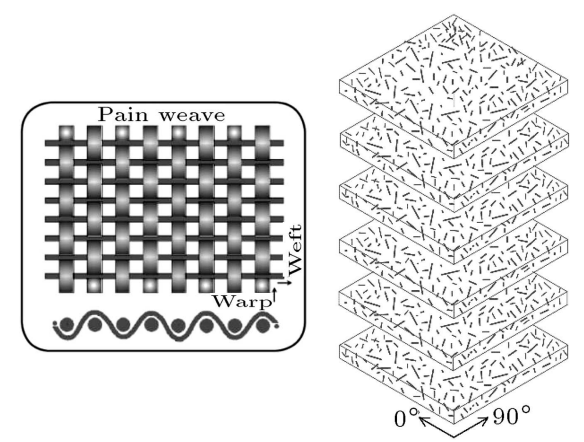
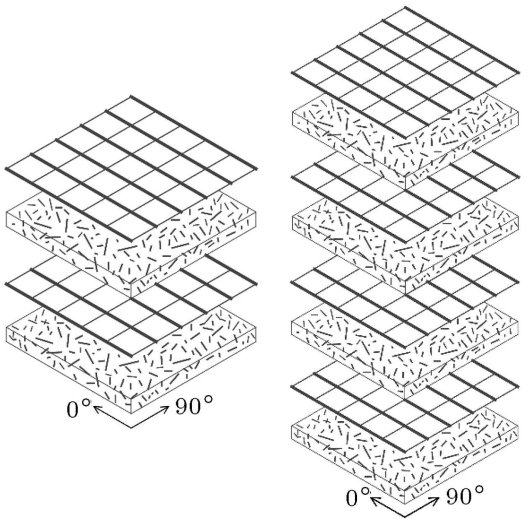

Figure 2. Fabric pattern and layers of S1, S2, and S3.

$\mathrm{S} 3$ is shown in Figure 2. Since the glass fabric in the composite structure was woven $80 \%$ along the longitudinal direction $\left(0^{\circ}\right)$ and $20 \%$ in the transverse direction $\left(90^{\circ}\right)$, it can be considered quasi-unidirectional. The fiber failure energy values were defined by the tensile and compressive process in the 0-degree fiber direction (warp). The tensile and compressive operations in the direction of $90^{\circ}$ (weft) indicated the matrix damage energy values. There was no direction difference since S1 contained only chopped fiber.

\subsection{Method}

Test specimens were prepared using the water-jet technique in accordance with the dimensions shown in Figure 3. The specimen followed the fracture mechanics test method described in ASTM E-399 and ISO-13586 standards (Figure 3) [28,29]. Compact tension/compression test type specimens were designed using a pre-opened notch in such a way that the crack could propagate. The test specimens seen in Figure 3 have a pre-crack. This pre-crack means a pre-load that ensures the damage starts the same way [30].

The Compact Tension (CT) and Compact Compression (CC) tests were conducted using an Instron3369 universal testing machine with a load capacity of $50 \mathrm{kN}$. The specimens were previously linked with required pins of appropriate thickness. The tests were performed at a constant speed control of $10 \mathrm{~mm} / \mathrm{min}$ and displacement versus force change were measured instantaneously. By applying load through pins that were inserted into the holes on the notched sample, the fracture was created. The failure crack started from a point of the notch and kept through the specimen. The instantaneous load and displacement values were recorded by the computer during the test to calculate the fracture toughness.

The fracture was described as the mechanical split of a rigid body due to the stress effect and the material fractures were classified as brittle or ductile fractures. The brittle materials absorbed low energy, while the ductile materials absorbed much more energy. The fracture toughness was correlated with spending energy amount to crack failure or deformation occurrence. The fracture resistance is defined in terms of the stress intensity factor ' $K_{Q}$ ' and the strain energy release rate ' $G_{Q}$ ' [6].

The critical energy release rate was calculated using the Eq. (1) and the assumed unit was $\mathrm{kJ} / \mathrm{m}^{2}$ :

$$
G_{Q}=\frac{W_{B}}{h \cdot w \cdot \phi}
$$

$W_{B}$ is the energy to break $(\mathrm{kJ}) ; h$ is the specimen thickness $(\mathrm{m}) ; w$ is the specimen width $(0.05 \mathrm{~m})$; and
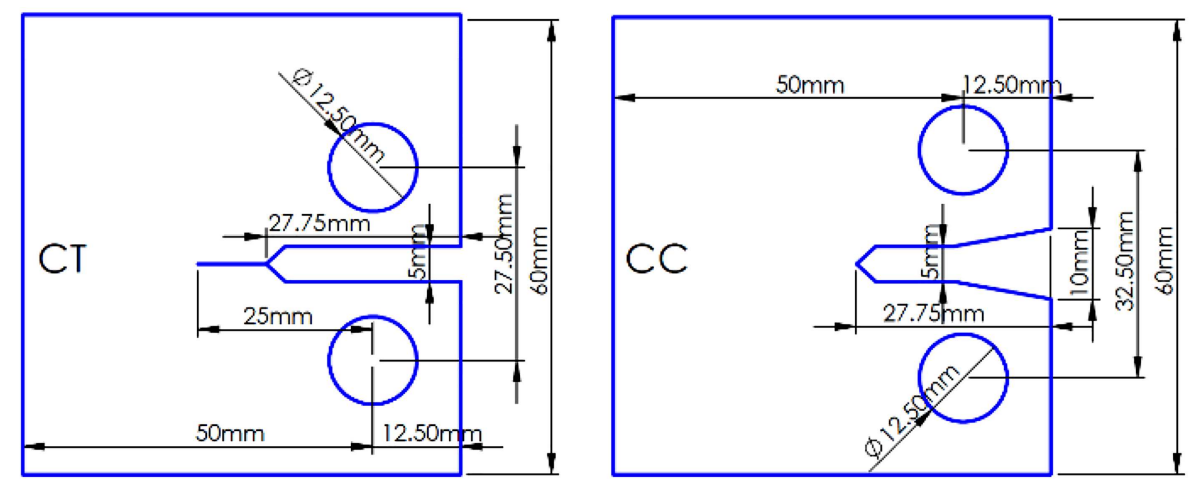

Figure 3. Specimens of Compact Tension (CT) and Compact Compression (CC) tests. 
$\phi$ is the energy calibration factor (0.199) depending on the crack length [28]. The $W_{B}$ was found using Eq. (2):

$$
W_{B}=\frac{0.95 \cdot F_{Q} \cdot s}{2} .
$$

$F_{Q}$ and $s$ are the load $(\mathrm{kN})$ and displacement $(\mathrm{m})$ at crack growth, respectively.

The elasticity modulus of fracture $E_{f}$ was related to the mechanical fracture properties $G_{Q}$ and $K_{Q}$ using Eq. (3) as follows:

$$
E_{f}=\frac{K_{Q}^{2}}{G_{I C}} .
$$

$K_{Q}$ is the critical stress intensity factor and it was calculated using Eq. (4) as follows:

$$
K_{Q}=f \frac{F_{Q}}{h \sqrt{w}} .
$$

$f$ is the geometry calibration factor and its value was 8.34 depending on the crack length. The calibration factor taken from the tables of ISO-13586, was determined by the ratio of crack length to specimen width.

\section{Results and discussion}

In this section, firstly the diagrams containing the force-displacement curves are given and the final states of the specimens are evaluated. In agreement with the findings of Hallet, in the present study, the first minor load drop showed the beginning of the damage and the last major load drop showed the quality of the damage development [31]. The initial and maximum fracture load values were recorded during the tension and compression tests for each specimen, and the energy rates are presented in Tables 2 and 3 . Then, the fracture onset toughness results were compared and the fracture elastic moduli were calculated.

when the damage is started, the crack growth model controlled the composite material response. The fiber-reinforced composites have four types of failure including breaking of fibers under stress; curl of fibers under pressure; matrix cracking in transverse shear and stress; matrix crushing under transverse shear and compression stress [9]. The different kinds of failure modes of plies proportional to the loading modes are

\begin{tabular}{|c|c|c|c|c|c|c|c|c|}
\hline \multirow{3}{*}{$\mathbf{0}^{\circ}$} & \multicolumn{4}{|c|}{ Load and toughness at minor-drop } & \multicolumn{4}{|c|}{ Maximum load and toughness } \\
\hline & \multicolumn{2}{|c|}{ Tensile } & \multicolumn{2}{|c|}{ Compressive } & \multicolumn{2}{|c|}{ Tensile } & \multicolumn{2}{|c|}{ Compressive } \\
\hline & $\begin{array}{c}F \\
(\mathrm{~N})\end{array}$ & $\begin{array}{c}G \\
\left(\mathbf{k J} / \mathbf{m}^{2}\right)\end{array}$ & $\begin{array}{c}F \\
(\mathrm{~N})\end{array}$ & $\begin{array}{c}G \\
\left(\mathrm{~kJ} / \mathrm{m}^{2}\right)\end{array}$ & $\begin{array}{c}F \\
(\mathrm{~N})\end{array}$ & $\begin{array}{c}G \\
\left(\mathrm{~kJ} / \mathbf{m}^{2}\right)\end{array}$ & $\begin{array}{c}F \\
(\mathrm{~N})\end{array}$ & $\begin{array}{c}G \\
\left(\mathrm{~kJ} / \mathrm{m}^{2}\right)\end{array}$ \\
\hline $\mathrm{S} 1$ & $\begin{array}{c}1027 \\
(4.0 \mathrm{~mm})\end{array}$ & 41.03 & $\begin{array}{c}1422 \\
(2.2 \mathrm{~mm})\end{array}$ & 31.83 & $\begin{array}{c}1027 \\
(4.0 \mathrm{~mm})\end{array}$ & 41.03 & $\begin{array}{c}1617 \\
(4.0 \mathrm{~mm})\end{array}$ & 64.35 \\
\hline $\mathrm{S} 2$ & $\begin{array}{c}1404 \\
(4.4 \mathrm{~mm})\end{array}$ & 62.61 & $\begin{array}{c}1561 \\
(1.9 \mathrm{~mm})\end{array}$ & 30.28 & $\begin{array}{c}1493 \\
(6.1 \mathrm{~mm})\end{array}$ & 91.09 & $\begin{array}{c}2323 \\
(4.8 \mathrm{~mm})\end{array}$ & 111.31 \\
\hline S3 & $\begin{array}{c}2348 \\
(6.2 \mathrm{~mm})\end{array}$ & 161.24 & $\begin{array}{c}1904 \\
(1.7 \mathrm{~mm})\end{array}$ & 35.95 & $\begin{array}{c}2573 \\
(7.5 \mathrm{~mm})\end{array}$ & 215.24 & $\begin{array}{c}2706 \\
(4.5 \mathrm{~mm}) \\
\end{array}$ & 136.70 \\
\hline
\end{tabular}
shown schematically in the figures [32].

Table 2. Comparison of the CT/CC longitudinal direction test results for the specimens.

\begin{tabular}{|c|c|c|c|c|c|c|c|c|}
\hline \multirow{3}{*}{$90^{\circ}$} & \multicolumn{4}{|c|}{ Load and toughness at minor-drop } & \multicolumn{4}{|c|}{ Maximum load and toughness } \\
\hline & \multicolumn{2}{|c|}{ Tensile } & \multicolumn{2}{|c|}{ Compressive } & \multicolumn{2}{|c|}{ Tensile } & \multicolumn{2}{|c|}{ Compressive } \\
\hline & $\begin{array}{c}F \\
(\mathbf{N})\end{array}$ & $\begin{array}{c}G \\
\left(\mathbf{k J} / \mathbf{m}^{2}\right)\end{array}$ & $\begin{array}{c}F \\
(\mathbf{N})\end{array}$ & $\begin{array}{c}G \\
\left(\mathrm{~kJ} / \mathrm{m}^{2}\right)\end{array}$ & $\begin{array}{c}F \\
(\mathrm{~N})\end{array}$ & $\begin{array}{c}G \\
\left(\mathrm{~kJ} / \mathrm{m}^{2}\right)\end{array}$ & $\begin{array}{c}F \\
(\mathrm{~N})\end{array}$ & $\begin{array}{c}G \\
\left(\mathrm{~kJ} / \mathrm{m}^{2}\right)\end{array}$ \\
\hline $\mathrm{S} 1$ & $\begin{array}{c}779 \\
(2.7 \mathrm{~mm})\end{array}$ & 21.07 & $\begin{array}{c}1369 \\
(1.6 \mathrm{~mm})\end{array}$ & 22.47 & $\begin{array}{c}785 \\
(3.0 \mathrm{~mm})\end{array}$ & 23.42 & $\begin{array}{c}1982 \\
(4.7 \mathrm{~mm})\end{array}$ & 93.96 \\
\hline $\mathrm{S} 2$ & $\begin{array}{c}899 \\
(2.4 \mathrm{~mm})\end{array}$ & 22.21 & $\begin{array}{c}1721 \\
(1.9 \mathrm{~mm})\end{array}$ & 33.10 & $\begin{array}{c}924 \\
(2.7 \mathrm{~mm})\end{array}$ & 24.82 & $\begin{array}{c}2474 \\
(4.9 \mathrm{~mm})\end{array}$ & 121.39 \\
\hline S3 & $\begin{array}{c}1161 \\
(2.6 \mathrm{~mm})\end{array}$ & 34.40 & $\begin{array}{c}2052 \\
(1.6 \mathrm{~mm})\end{array}$ & 37.98 & $\begin{array}{c}1397 \\
(3.9 \mathrm{~mm})\end{array}$ & 61.52 & $\begin{array}{c}2273 \\
(2.5 \mathrm{~mm})\end{array}$ & 64.79 \\
\hline
\end{tabular}

Table 3. Comparison of the CT/CC transverse direction test results for the specimens. 


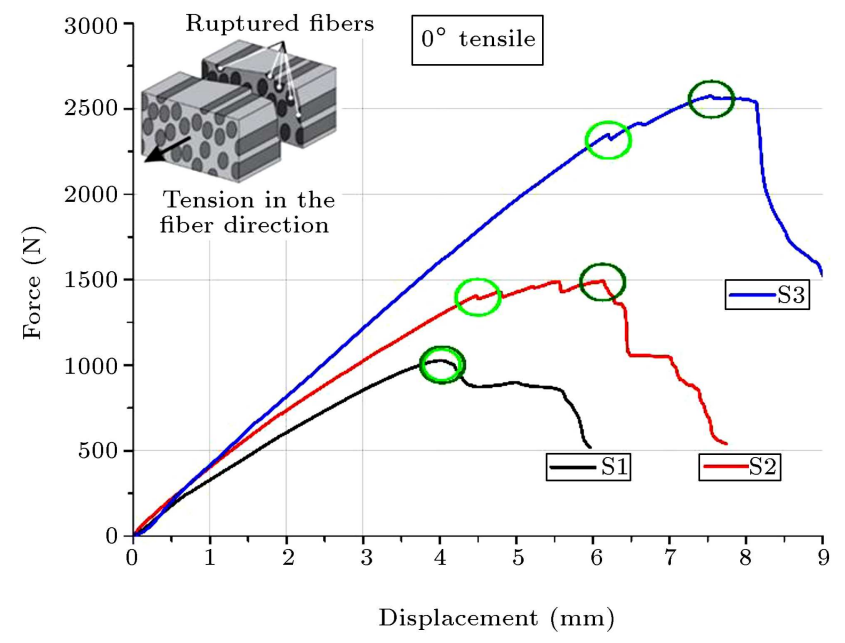

Figure 4. Longitudinally fracture tensile curves.

To examine the effect of the fiber reinforcement on the fracture toughness, the force-displacement curves obtained from the longitudinally fracture tension tests are shown in Figure 4. The damage initial and peak points are marked on each curve. The exact values corresponding to the specified points are listed in Table 2. As the tensile force increased, the amount of displacement where the maximum load occurred, increased too. The S3 was taken as the material having the highest force since it contained maximal reinforcement with four fabric layers and a $57 \%$ total fiber ratio. The $\mathrm{S} 1$ acted as ductile-isotropic materials because it had only chopped fiber. The initial response of S1 appeared nonlinear. The damage development, on the other hand, continued with the gradual descendence of force, unlike S2 and S3. This could be taken as supporting evidence to explain that the energy dissipation occurs with damage, but it should be noted that only the fracture is excluded from this rule. Another argument that could be conceived is that the randomly distributed fiber was concentrated locally or the fiber-polymer bonding varied regionally. As to the other specimens, S2 and S3, more than one brittle rupture drop happened due to the fact that they had continuous fibers. The force increased after the first fiber breakage due to the continuous fiber density. This could be taken as supporting evidence by which the following facts could be explained:

1. All fibers do not break simultaneously;

2. The fibers that continue to show regional resistance to the applied load, gradually rupture.

On the other hand, the progress of the damage of the chopped fiber reinforced composite resulted from the torn, not from a hard break.

Figure 5 shows the images of the specimens after the longitudinal CT test. The crack progression occurred in a linear form for S1. While the direction of the crack propagation gradually changed for $\mathrm{S} 2$, due to the continuous fiber density, which showed high resistance to the breakage, a sharp change was observed after the fiber breakage. The damage occurred in the marked regions due to the partial compressive load. Kuppusamy and Tomlinson investigated the compressive regions that occur in the CT test, and a clamp development study was carried out to reduce these failures [33]. In S3, the matrix was subjected to shear force parallel to the continuous fiber until the fiber breakage, and pull-outs occurred.

Force versus displacement curves obtained by longitudinal fracture compression tests are shown in Figure 6. A compressive load of up to $5 \mathrm{~mm}$ was applied to the composites. The onset and peak compressive damage forces for each specimen are given in Table 2. Similar to what observed for compression, the sequence of the tension was not changed, and the initial and maximum force values of the damage were determined to be $\mathrm{S} 3>\mathrm{S} 2>\mathrm{S} 1$ ranging from high to low. The response of the composite materials to the compression was stronger compared to that of the tensile operation. The continuous fiber showed great resistance to tensile, while both the matrix structure and the chopped fiber tolerated the applied load. Similar to what is observed for the tensile force, the specimen loaddisplacement responses were nonlinear before fracture initiation, indicating that another damage occurred before fracture. The force curve of S1 almost flattened
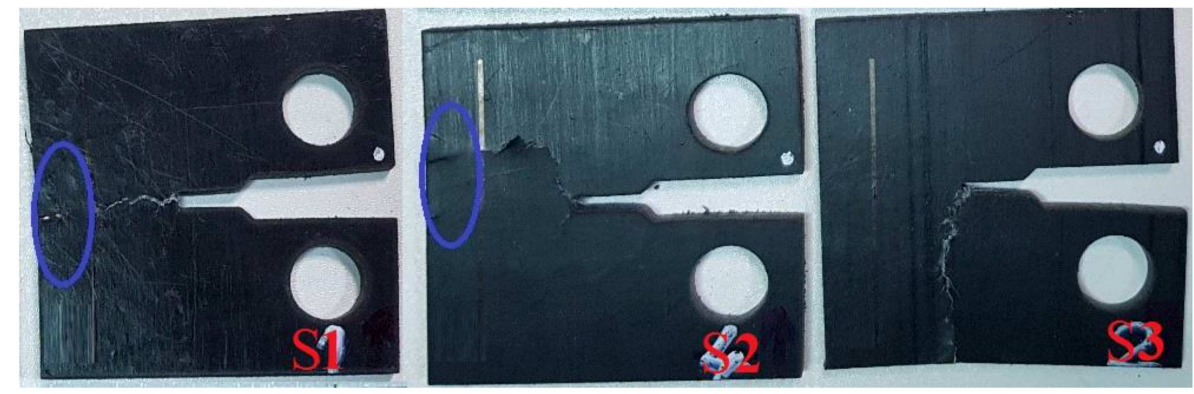

Figure 5. Photograph of the specimens for longitudinal tension tests. 


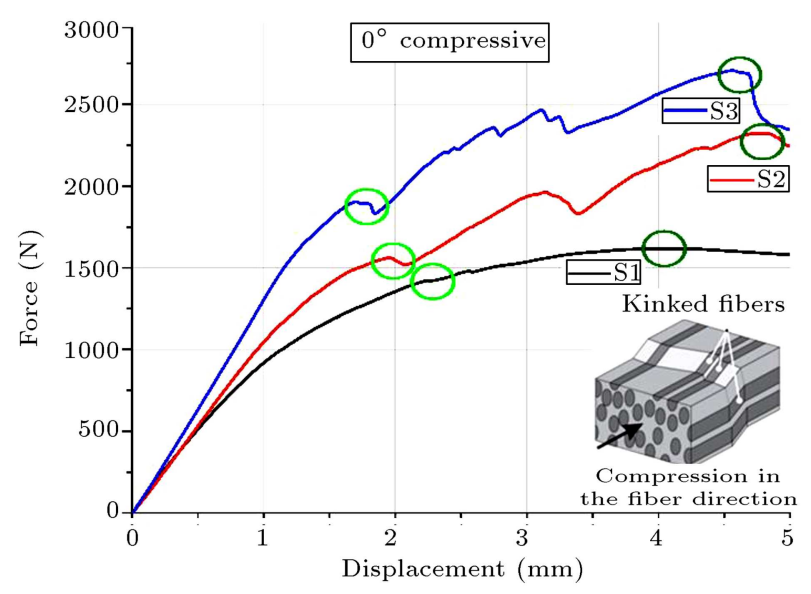

Figure 6. Longitudinally fracture compressive curves.

after the start of damage. For S3 and S2, it was observed that up to $74 \%$ of the peak of the load force change was linear and the crack propagation occurred in distinct jumps. These findings are in agreement with that of Catalanotti et al. [26].

Figure 7 shows the situations of the fracture specimens after the longitudinal compression experiments. In compression tests, the damage developed in the form of planarly shearing parallel to the force direction. While the damage progress of S3 was irregular, the initial damage and the progress of the other specimens took place in a single line. The heavy distribution of damage occurred in all specimens, which could discredit the assumptions inherent in the conventional fracture characterization approach.

By examining the force-placement changes it is revealed that the thickness, fiber style, and ratio affected the onset and development of damage. In the longitudinal tension process, the increase of the maximum force led to the increase of displacement. Both longitudinal and transverse tensile forces were smaller in S1 containing only chopped fiber, then in S2 with $39 \%$ fiber ratio and S3 with $57 \%$ fiber ratio. When the longitudinal compressive load is applied, the change was monitored in the same way; when the compressive load was implemented transversely, S2 showed more resistance to fracture than $\mathrm{S} 3$ after the start of damage.

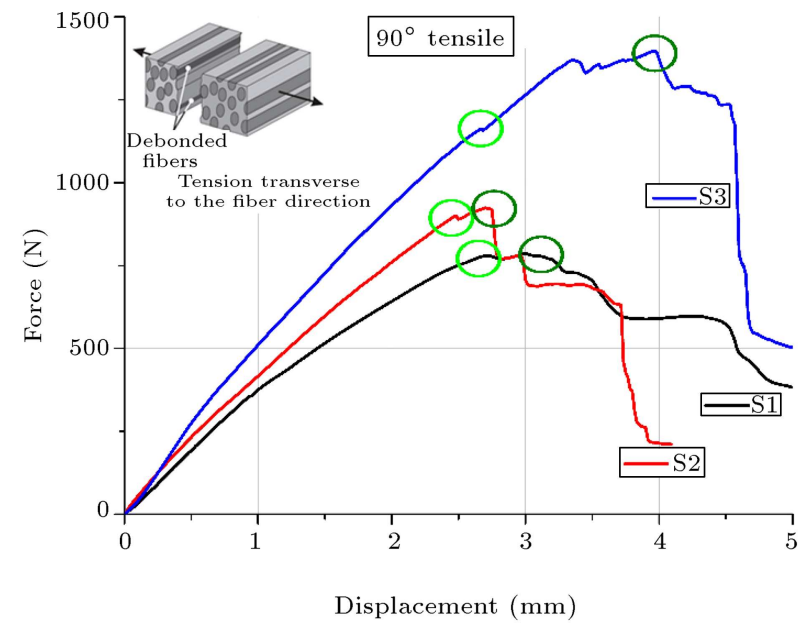

Figure 8. Transversely fracture tensile curves.

The force and displacement curves of the materials subjected to the transversely fracture tensile are shown in Figure 8. Due to the existence of the precrack in the middle of the specimens, the force curves followed a similar increasing trend, and the curves remained nearly linear until the start of damage; as pointed out by Blanco et al. [23]. Both the force and displacement values in the transverse direction were significantly lower compared to that of the longitudinal tensile, and these values are given in Table 3 . The rate of increase recorded between the start of damage and the maximum force occurred during the damage development was $20 \%$ for S3 due to the effect of continuous fiber.

Figure 9 shows the final states of the specimens after the transverse tension test. The matrix cracking played a dominant role in the damage development. It was observed that the length elongations were equal. The deformation that started in the marked bearing area of S1 caused the outward shearing failure to be appeared.

The force and displacement curves of the composites which were subjected to the transverse compressive load are shown in Figure 10. The compressive load was stopped at $5 \mathrm{~mm}$ of displacement. The $\mathrm{S} 1$ exhibited a fairly steady state after the force first sudden gradient.
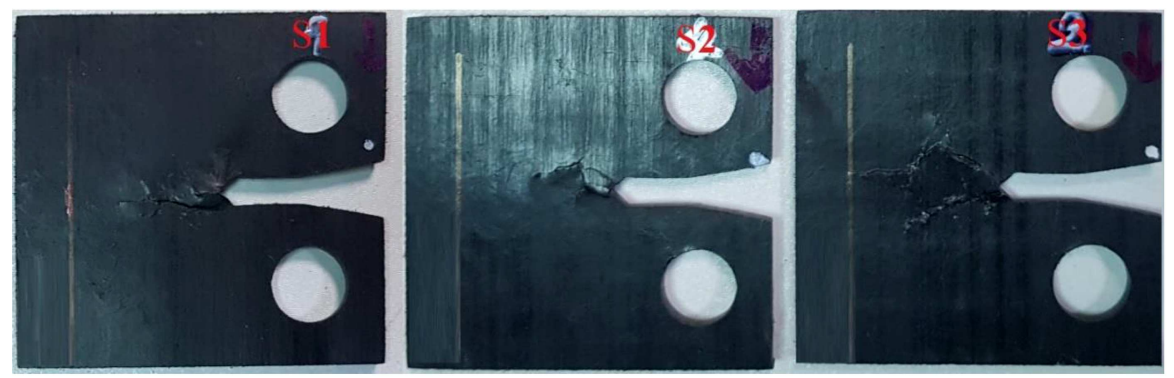

Figure 7. The specimens for longitudinal compression tests. 


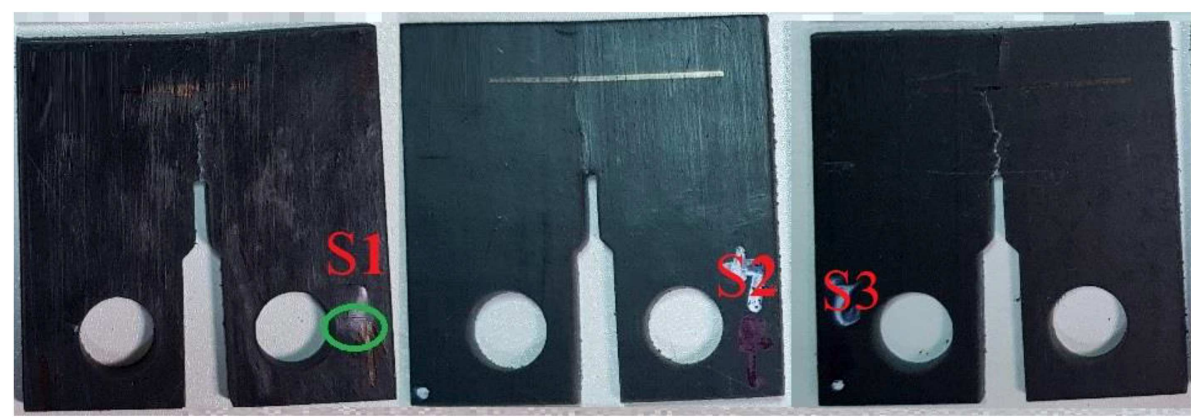

Figure 9. The specimens for transverse tension tests.

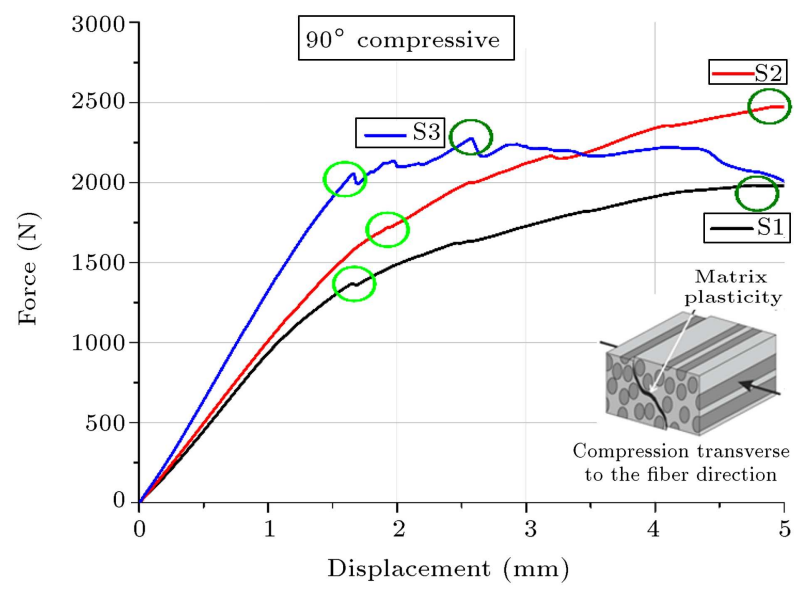

Figure 10. Transversely fracture compressive curves.

For the S1 and S2 of the same thickness, the force values versus displacement increased consistently and step-by-step. Although the damage initial force of S3 was higher than others, its maximum force was lower than S2. This showed that the chopped fiber and thickness are more effective against crushing.

Figure 11 shows the failure states of the specimens after the transverse compression test. In the $\mathrm{S} 2$, a rupture occurred due to the tensile load. The back marked region is seen on the specimen photo. The bearings are the spaces in which the pins that apply load to the specimen are inserted. The S3 exhibited maximum performance under all load and in all directions, besides, the fracture energy under compression condition was $2.6 \%$ higher compared to the tension resulting from the effect of chopped fiber. Although the S1 contained only chopped fibers, it performance was better in the longitudinal direction than in the transverse direction, due to the effect of the sheet production direction. Like the rolling direction of metals, the molding direction of plastics, and accordingly the manufacturing direction of composite materials increase the mechanical properties [34]. The fracture energies depending on the composite types differed significantly in the longitudinal direction compared to the transverse direction.

Harris and Morris suggested that for the centernotched specimens, the 'significant pop-in load' (the force corresponding to the first clear transposition) should be used instead of the traditional maximum load. The fracture energy calculated from the pop-in point showed a more positive correlation compared to those obtained by other methods [35]. The longitudinal tensile and compressive fracture initial energies are compared in Figure 12. The translaminar damage occurred in the longitudinal experiments, thereby the fibers ruptured during tensile state and kinked during compression state. For all specimens, in the tensile state, the fracture energies were higher than in the compressive state. It was found that the composite with the lowest damage energy rate was $\mathrm{S} 1$, which contained only the chopped fiber. The S3, containing the highest level of fiber ratio and continuous fiber layers, showed great resistance to damage, especially
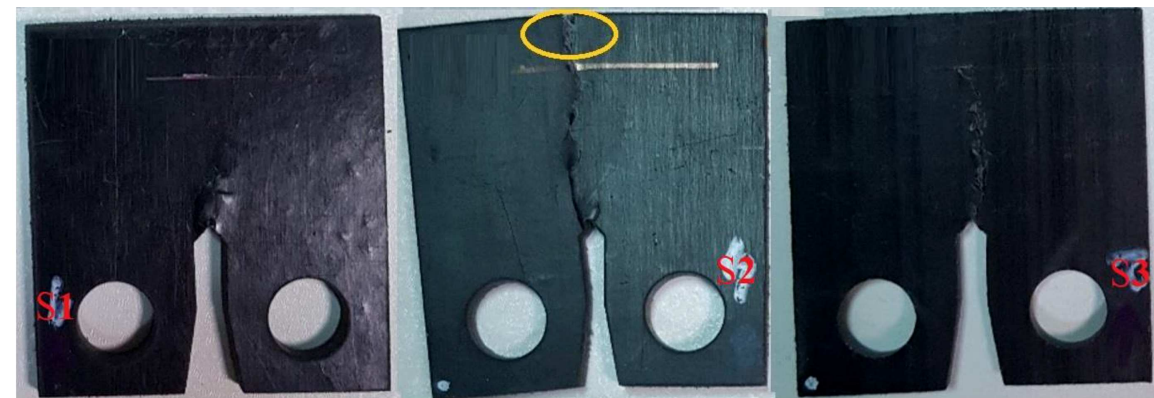

Figure 11. The specimens for transverse compression tests. 


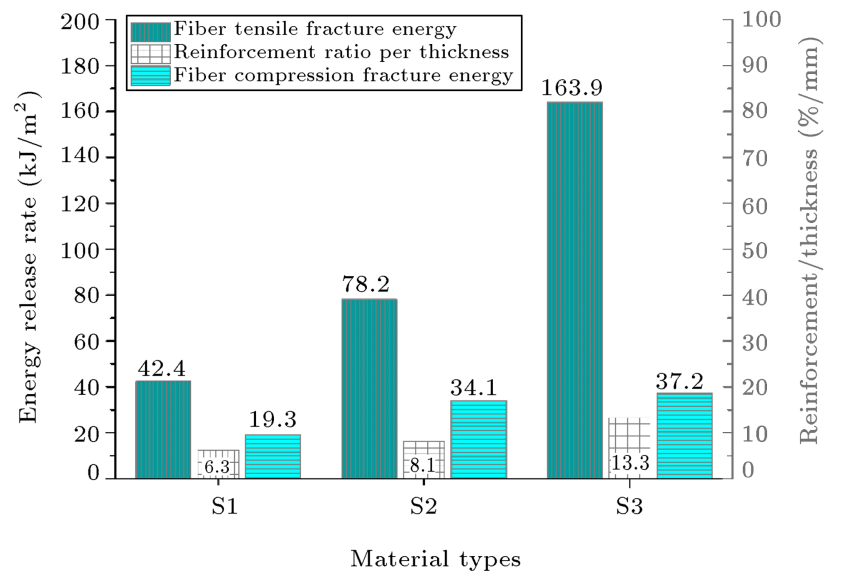

Figure 12. Fiber fracture energies in tensile and compressive situations (initiation values).

under the tensile condition. The fiber ratios and thicknesses of S3 and S2, which were reinforced with woven fiber, had little effect on the fracture energy rates in the case of the longitudinal compressive state. By comparing the S1 and S2 it is revealed that the effect of the continuous fiber on the damage evolution was higher compared to that of chopped fiber.

The damage occurred in the form of debonded fibers when the transverse tensile load was applied and the cracked matrix appeared under compressive load. In Figure 13, the transverse energy rates obtained in the tension and compression tests are compared. The variation of the fracture energy rate between tensile and compressive states was observed for S1. For S3, the fracture energy rate for S3 was higher in both load conditions compared to the other conditions, since the amount of continuous fiber was larger in the longitudinal direction. Furtado et al. reported that the fiber plies in the $0^{\circ}$ direction resulted in an increase of the intra-laminar fracture toughness [20]. In agreement with these findings the result of the present study

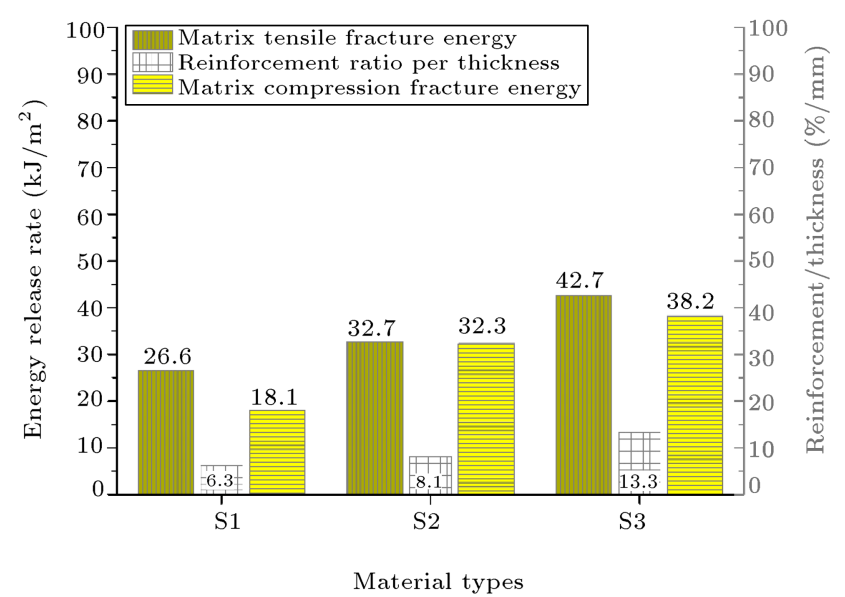

Figure 13. Matrix fracture energies in tensile and compressive situations (initiation values).

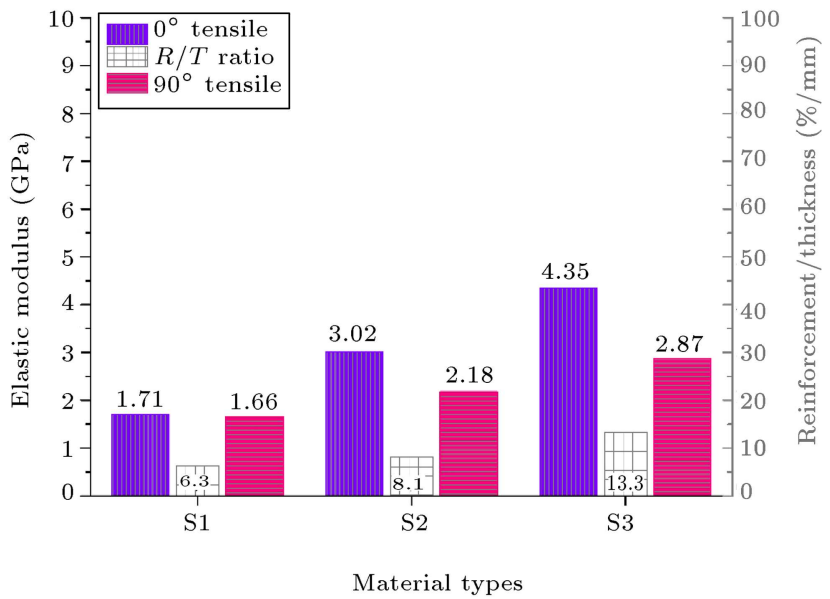

Figure 14. Comparison of fracture elastic moduli.

showed that due to the fiber density, in the longitudinal direction $\left(0^{\circ}\right)$, the tensile fracture toughness was higher compared to the conditions of the transverse direction $\left(90^{\circ}\right)$.

The longitudinal and transverse elastic moduli calculated after tension tests are shown in Figure 14. The chopped fibers bridged the crack, and prevented the extension of the crack for S1, and pulled the fibers out of the matrix for other specimens. Thus, the elastic strain energy is stored both longitudinally and transversely. The elastic modulus in both directions of $\mathrm{S} 1$ was similar, as expected. The elastic moduli of S2 and S3, varied relative to the fabric layer due to the brittle characteristic of the continuous fiber.

\section{Conclusion}

In this study, the compact tension/compression tests were performed to detect the fracture toughness of the hybrid glass fiber reinforced polypropylene composite laminates with three different compositions and, the intralaminar and translaminar failure modes were investigated, and they were evaluated in terms of the fiber type, ratio, and direction.

As a result of the longitudinal tension, the damage developed gradually in the form of the translaminar fiber breaking in the composites containing continuous fibers. In case of the longitudinal compression, the damage developed in the form of the fiber buckling in the composite with higher continuous fiber content and in the form of intralaminar shearing in other materials. In the transverse tension process, too the fiber-matrix debonding occurred in the form of the intralaminar deformation in the composites. In the transverse compression process, the intralaminar matrix cracking caused the failure to be occurred in the specimens.

In the event of tension, the initial fracture energy release rates were higher than that of the compression test. The highest fracture initial energy was detected 
in the composite with four layers of woven fiber and reached $163.9 \mathrm{~kJ} / \mathrm{m}^{2}$ for the longitudinal tensile. The lowest fracture initial energy was determined to be $18.1 \mathrm{~kJ} / \mathrm{m}^{2}$ for the composite containing only chopped fiber in the transverse direction. It was found that the longitudinal fracture elastic moduli were greater than the transverse one, and the fabric yarn density played a dominant role in the elastic module.

\section{Acknowledgments}

We would like to thank Quadrant Plastic Composites AG for supplying the composite materials used in this study, as well as the Gazi University Rectorship Unit of Scientific Research Projects for supporting this study within the scope of the project numbered 07/2018-15.

\section{Nomenclature}

$\begin{array}{ll}C C & \text { Compact Compression } \\ C T & \text { Compact Tension } \\ E_{f} & \text { Elasticity modulus }(\mathrm{Pa}) \\ F & \text { Deformation load }(\mathrm{N}) \\ f & \text { Geometrical calibration factor } \\ G & \text { Fracture energy release rate }\left(\mathrm{J} / \mathrm{m}^{2}\right) \\ K & \text { Critical stress intensity }\left(\mathrm{N} / \mathrm{m}^{3 / 2}\right) \\ h & \text { Specimen thickness }(\mathrm{m}) \\ s & \text { Crack displacement }(\mathrm{m}) \\ W_{B} & \text { Energy at break }(\mathrm{J}) \\ w & \text { Specimen width }(\mathrm{m}) \\ \phi & \text { Energy calibration factor }\end{array}$

\section{References}

1. Sharma, N., Mahapatra, T.R., and Panda, S.K. "Vibro-acoustic analysis of laminated composite plate structure using structure-dependent radiation modes: An experimental validation", Scientia Iranica, B, 25(5), pp. 2706-2721 (2018).

2. Abedi, M., Torshizi, S.E.M., and Sarfaraz, R. "Experimental characterization of fracture of glass fiber reinforced composites laminates subjected to freeze-thaw cycles", Fatigue \& Fracture of Engineering Materials \& Structures, 43, pp. 242-249 (2020).

3. Vishwas, M., Joladarashi, S., and Kulkarni, S.M. "Comparative study of damage behavior of synthetic and natural fiber-reinforced brittle composite and natural fiber-reinforced flexible composite subjected to low-velocity impact", Scientia Iranica, B, 27(1), pp. 341-349 (2020).

4. Tanzi, M.C., Fare, S., and Candiani, G. "Chapter 1 Organization, structure, and properties of materials", Foundations of Biomaterials Engineering, 1st Ed., pp. 3-103 (2019).
5. Davies, G., Materials for Automobile Bodies, Elsevier, Oxford, pp. 94-143 (2012).

6. Prasad, S.M.S., Venkatesha, C.S., and Jayaraju, T. "Experimental methods of determining fracture toughness of fiber reinforced polymer composites under various loading conditions", Journal of Minerals and Materials Characterization and Engineering, 10(13), pp. 1263-1275 (2011).

7. Mohammed, Y., Hassan, M.K., and Hashem, A.M. "Finite element computational approach of fracture toughness in composite compact-tension specimen", International Journal of Mechanical \& Mechatronics Engineering, 12(4), pp. 57-61 (2012).

8. Lisle, T., Bouvet, C., Hongkarnjanakul, B., et al. "Measure of fracture toughness of compressive fiber failure in composite structures using infrared thermography", Composites Science and Technology, 112, pp. 22-33 (2015).

9. Sato, N., Hojo, M., and Nishikawa, M. "Intralaminar fatigue crack growth properties of conventional and interlayer toughened CFRP laminate under mode I loading", Composites Part A: Appl Sci Manuf., 68, pp. 202-211 (2015).

10. Morais, A.B., Rebelo, C.C., Castro, P.M.S.T., et al. "Interlaminar fracture studies in Portugal: past, present and future", Fatigue \& Fracture of Engineering Materials \& Structures, 27, pp. 767-773 (2004).

11. Laffan, M.J., Pinho, S.T., Robinson, P., et al. "Translaminar fracture toughness testing of composites: A review", Polymer Testing, 31, pp. 481-489 (2012).

12. Xu, X., Wisnom, M.R., and Hallett, S.R. "Deducing the R-curve for trans-laminar fracture from a virtual Over-height Compact Tension (OCT) test", Composites Part A: Appl. Sci. Manuf., 118, pp. 162-170 (2019).

13. Marin, L., Gonzalez, E.V., Maimi, P., et al. "Нygrothermal effects on the translaminar fracture toughness of crossply carbon/epoxy laminates: Failure mechanisms", Composites Science and Technology, 122, pp. 130-139 (2016).

14. Ma, J., Mo, M.S., Du, X.S., et al. "Effect of inorganic nanoparticles on mechanical property, fracture toughness and toughening mechanism of two epoxy systems", Polymer, 49, pp. 3510-3523 (2008).

15. Trappe, V., Günzel, S., and Jaunich, M. "Correlation between crack propagation rate and cure process of epoxy resins", Polymer Testing, 31, pp. 654-659 (2012).

16. Pinho, S.T., Robinson, P., and Iannucci, L. "Fracture toughness of the tensile and compressive fibre failure modes in laminated composites", Composites Science and Technology, 66, pp. 2069-2079 (2006).

17. Katafiasz, T.J., Iannucci, L., and Greenhalgh, E.S. "Development of a novel compact tension specimen to 
mitigate premature compression and buckling failure modes within fibre hybrid epoxy composites", Composite Structures, 207, pp. 93-107 (2019).

18. Gigliotti, L. and Pinho, S.T. "Translaminar fracture toughness of NCF composites with multiaxial blankets", Materials \& Design, 94, pp. 410-416 (2016).

19. Pimenta, S. and Pinho, S. "An analytical model for the translaminar fracture toughness of fibre composites with stochastic quasi-fractal fracture surfaces", Journal of the Mechanics and Physics of Solids, 66, pp. 78-102 (2014).

20. Furtado, C., Arteiro, A., Linde, P., et al. "Is there a ply thickness effect on the mode I intralaminar fracture toughness of composite laminates", Theoretical and Applied Fracture Mechanics, 107, p. 102473 (2020).

21. Duigou, A.L., Davies, P., and Baley, C. "Macroscopic analysis of interfacial properties of flax/PLLA biocomposites", Composites Science and Technology, 70(11), pp. 1612-1620 (2010).

22. Kinloch, A.J., Taylor, A.C., Techapaitoon, M., et al. "From matrix nano- and micro-phase tougheners to composite macro-properties", Philosophical Transactions of the Royal Society A, 374, p. 20150275 (2016).

23. Blanco, N., Trias, D., Pinho, S.T., et al. "Intralaminar fracture toughness characterisation of woven composite laminates, part II: experimental characterization", Engineering Fracture Mechanics, 131, pp. 361-370 (2014).

24. Blanco, N., Trias, D., Pinho, S.T., et al. "Intralaminar fracture toughness characterisation of woven composite laminates. Part I: Design and analysis of a Compact Tension (CT) specimen", Engineering Fracture Mechanics, 131, pp. 349-360 (2014).

25. Chevalier, J., Morelle, X.P., Camanho, P.P., et al. "On a unique fracture micromechanism for highly crosslinked epoxy resins", Journal of the Mechanics and Physics of Solids, 122, pp. 502-519 (2019).

26. Catalanotti, G., Camanho, P.P., Xavier, J., et al. "Measurement of resistance curves in the longitudinal failure of composites using digital image correlation", Composites Science and Technology, 70, pp. 1986-1993 (2010).

27. Ahmad, M., Ansari, R., and Rouhi, H. "Studying buckling of composite rods made of hybrid carbon fiber/carbon nanotube-reinforced polyimide using multi-scale FEM", Scientia Iranica, B, 27(1), pp. 252261 (2020).

28. ISO-13586, Plastics-Determination of fracture toughness (GIC and KIC)-Linear elastic fracture mechanics (LEFM) approach, Switzerland (2018).
29. ASTM-E399, Standard Test Method for Linear-Elastic Plane-Strain Fracture Toughness of Metallic Materials, United States of America (2017).

30. Li, X., Hallett, S.R., Wisnom, M.R., et al. "Experimental study of damage propagation in overheight compact tension tests", Composites Part A: Appl Sci Manuf., 40(12), pp. 1891-1899 (2009).

31. Hallett, S.R., Green, B.G., Jiang, W.G., et al. "An experimental and numerical investigation into the damage mechanisms in notched composites", Composites Part A: Appl Sci Manuf., 40(5), pp. 613-624 (2009).

32. O'Dwyer, D.J., O'Dowd, N.P., and McCarthy, C.T. "Numerical micromechanical investigation of interfacial strength parameters in a carbon fibre composite material", Journal of Composite Materials, 48(6), pp. 749-760 (2014).

33. Kuppusamy, N. and Tomlinson, R.A. "Repeatable precracking preparation for fracture testing of polymeric materials", Engineering Fracture Mechanics, 152, pp. 81-87 (2016).

34. Ozdemir, A.O., Karatas, C., and Yucesu, H.S. "Effect of fiber configuration on mechanical properties of thermoplastic composite laminates", Journal of Polytechnic, 24(2), pp. 599-607 (2021).

35. Harris, C.E. and Morris, D.H. "A comparison of the fracture behaviour of thick laminated composites utilizing compact tension, three-point bend, and centercracked tension specimens", Fracture Mechanics, 7, ASTM-STP-905, pp. 124-135 (1986).

\section{Biographies}

Abdullah Onur Özdemir graduated from Automotive Teaching and Mechanical Engineering bachelor programs. He received his MS degree in Mechanical Education. He is currently a PhD student in the field of Manufacturing Engineering. Ozdemir is also a Research Assistant in the Department of Automotive Engineering at Gazi University, Turkey. His researches interests include internal combustion engines and thermoplastic composites.

Çetin Karataş is a Professor of Manufacturing Engineering at Gazi University. He received his $\mathrm{PhD}$ from Gazi University in 1998. He has worked within the industry and academia in Turkey. He has published over 50 papers in scientific journals. He is a member of the editorial board of several journals. Also, he is the author of a book chapter and conducted various projects. His research interests include manufacturing engineering, powder metallurgy, and injection molding. 